\title{
Detection of Leakage Areas in an Earth Embankment from GPR Measurements and Permeability Logging
}

\author{
Raphaël Antoine, ${ }^{1,2}$ Cyrille Fauchard, ${ }^{1,3}$ Yannick Fargier, ${ }^{1}$ and Edouard Durand ${ }^{1}$ \\ ${ }^{1}$ Cerema, Direction Territoriale Normandie Centre, 76121 Le Grand Quevilly, France \\ ${ }^{2}$ Laboratoire Morphodynamique Continentale et Côtière (M2C), UMR 6143, Université de Rouen, 76451 Mont-Saint-Aignan, France \\ ${ }^{3}$ Advanced Mechanic and Material Engineering, Laboratoire d'Étude et de Caractérisation des Amorphes et des Polymères \\ (AMME-LECAP), Université de Rouen, 76800 Saint-Etienne-du-Rouvray, France
}

Correspondence should be addressed to Raphaël Antoine; raphael.antoine@cerema.fr

Received 10 December 2014; Accepted 27 January 2015

Academic Editor: Robert Tenzer

Copyright (C) 2015 Raphaël Antoine et al. This is an open access article distributed under the Creative Commons Attribution License, which permits unrestricted use, distribution, and reproduction in any medium, provided the original work is properly cited.

Ground penetrating radar (GPR) is a nondestructive method allowing the improvement of our knowledge of civil engineering structures. In particular, this method may be a nondestructive efficient tool for dike diagnosis and complete classical geotechnical methods. In this paper, we present GPR observations obtained on an earth embankment (crest and sloped paved revetment) in bad condition and located on the lateral canal of the Loire river (Saint Firmin, $80 \mathrm{~km}$ South East of Orléans). These measurements are combined with corings, visual inspection, and permeability logging performed with an updated drilling system, the Perméafor. This survey leads (i) to the detection of decompressed zones associated with leakage areas visible at the foot of the downstream slope and (ii) to the location of potentials voids underneath the paved revetment. This multidisciplinary approach complied with the dike inspection methodology proves its efficiency for the assessment of earth embankments.

\section{Introduction}

Regular maintenance and monitoring of vulnerable sites become important in the context of risk prevention and sustainable management. For example, water retention embankments may exhibit structural voids or deformations, substantial heterogeneities, or decompression phenomena, which suggest zones of weakness. Regular controls are necessary to monitor these sites and to provide useful information on the dike conditions to the stakeholder. For this purpose, a general methodology has been described in many works [1-3]. This methodology recommends the gathering of data issued from various preliminary studies such as historical research, geological and geomorphological study, and visual inspection. The use of geophysical methods combined with geotechnical surveys completes the aforementioned stages in order to provide the best possible assessment.

Various geophysical methods can be carried out for dike diagnosis. For example, multichannel analysis of seismic surface waves (MASW) and multichannel resistivity surveys, correlated with classical drilling testing, were used to characterize a karstic system located underneath a dike of the Loire river [4]. Crossline resistivity tomography was applied for the leakage pathways detection in an embankment dam [4]. Electrical resistivity method was used to delineate potential seepage zones [5]. A self-potential (SP) survey completed these measurements to delineate the seepage path. Recently, a case study reported the use of electrical resistivity tomography (ERT), frequency domain electromagnetic induction (FDEM), and GPR [6]. The authors also correlated these measurements with geotechnical investigations. GPR is rarely used on the French river network, because the majority of earth embankments are generally made from clayey and silty materials which prevents this technique from being used for the full height of the embankment. Nevertheless, it has been successfully used to detect anomalies very close to the surface both on dike slopes and on crests $[7,8]$. The GPR was carried out as a monitoring tool in Sweden [9] for dam assessment. A strong correlation was found between the porosity evaluated from boreholes GPR dielectric constant measurements and 


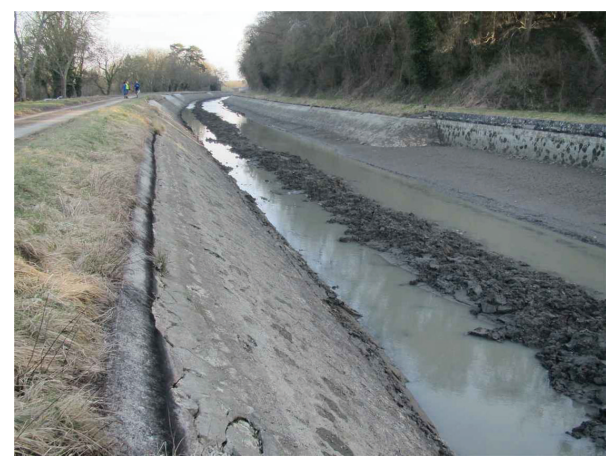

FIGURE 1: General view of the embankment.

dielectric permittivity model. Finally, the GPR was proposed as a noninvasive tool for quantifying the volumetric water content in a dike and for detecting termite nests inside dikes and dams and cracks in the sloping clay core $[10,11]$.

In our case study (earth embankment running alongside the Loire river, Saint Firmin, France, Figure 1), the canal was emptied for the geophysical survey. This is the reason why other methods such as spontaneous potentials [1214] were not used. Besides, GPR appears to be suitable for the characterization of potential defects underneath the paved revetment. Moreover, the dike is about $3 \mathrm{~m}$ in height. Thus, despite a limited depth of investigation, GPR remains a rapid and cost-effective method for the precise location of decompressed areas potentially associated with leakage pathways. Historical research [15] has shown that several resurgences have occurred for many years at the foot of the downstream slope. These leakages increased during 2011 and 2012, flooded the grasslands downstream, and induced drains of pluricentimetric diameter. The last resurgence was in February 2012.

In the first part of the paper, we describe the geological context and characterise the lithology and the morphology of the embankment. After a brief description of the basic principle of the GPR method and its implementation, the Perméafor system is presented. In the second part, the GPR signature of a structural void (a spillway) is studied. This observation serves as a qualitative reference for the characterization of potential voids inside the dike. Then, $400 \mathrm{MHz}$ and $200 \mathrm{MHz}$ GPR surveys were performed around two leakage areas. On the second zone, the results are correlated with visual inspection and in situ geotechnical testings (corings and permeability measurements). Finally, a model reporting the observed anomaly is proposed and discussed.

\section{Geological Context and Morphological Characterisation of the Embankment}

2.1. Geological Context and Lithology of the Embankment. The studied zone is $80 \mathrm{~km}$ South East of Orléans in the Commune of Saint Firmin-sur-Loire, along the canal, which runs parallel to the Loire river. In this region, the East bank of the canal is against the Loire river (digue des Galivores, Figures 1 and 2). This section of the canal was built towards the end of

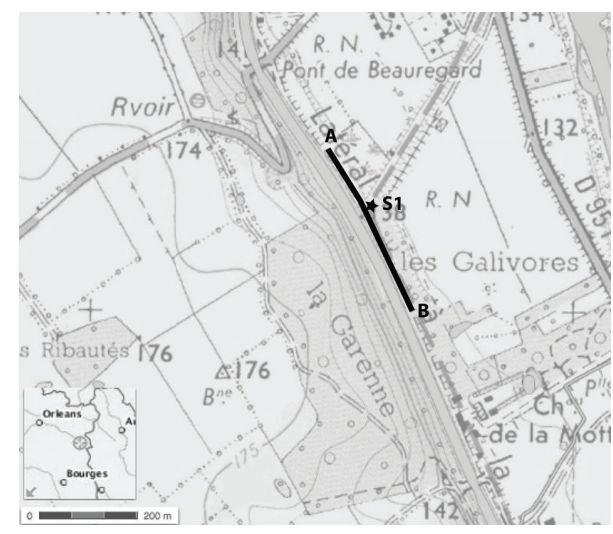

Figure 2: Location of the study zone and the S1 coring.

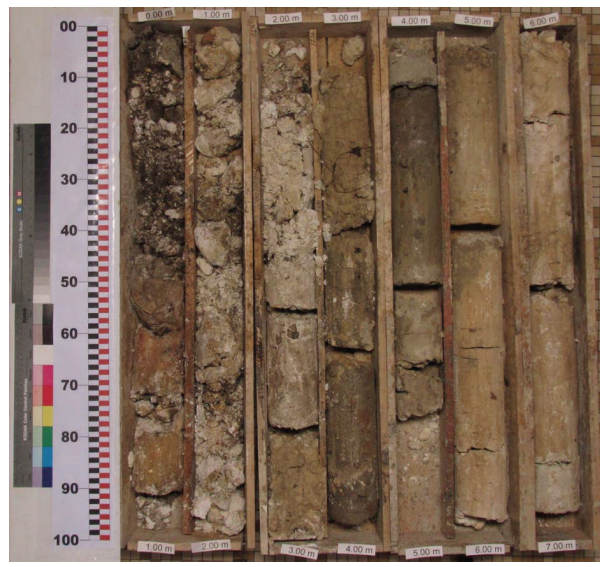

FIGURE 3: Soil samples obtained from the coring S1 on the crest of the embankment.

the 19th century, after the completion of the Pont-Canal de Briare (canal bridge).

The embankment is built on Turonian limestone and chalks. It is made of modern and ancient alluvial soils from the Loire lying above the substratum. A coring S1 has been performed in 2012 on the crest of the embankment (Figure $3[15]$ ). S1 is located on the crest just above a leakage zone studied in Section 4.3. It is composed of the following materials.

(i) The formation $\mathrm{A}$ (from 0 to $2-3 \mathrm{~m}$ in depth) is a filling material made of sand-gravel limestone with a clay matrix in variable proportions. Sand and silt materials, blocks of flint, and sandstone were observed in certain zones of the embankment, below the layer of vegetal soil, up to a depth of $50 \mathrm{~cm}$ to $70 \mathrm{~cm}$.

(ii) The formation $\mathrm{B}$ (from 4-5 to 6-7 $\mathrm{m}$ in depth) is a clayey filling material with limestone and chalk nodules. The clay-gravel filling material in S1 is liable to piping. In fact, granular materials were observed to be washed of their fine particles within the resurgence of February 2012. Furthermore, during the coring, the filling material was hardly compacted and very 


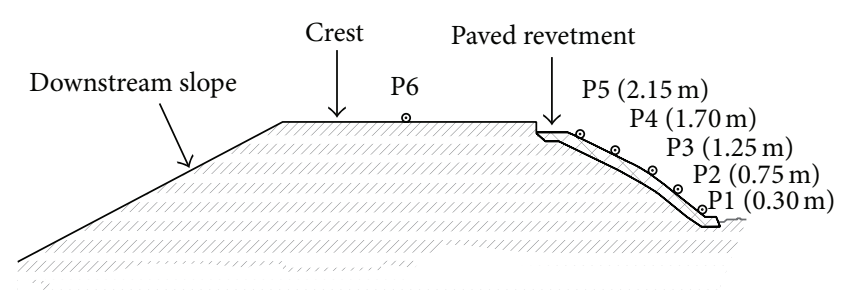

FIGURE 4: Transverse cross section of the embankment and location of the GPR profiles on the sloped paved revetment (P1 to P5) of the canal and on its crest (P6).

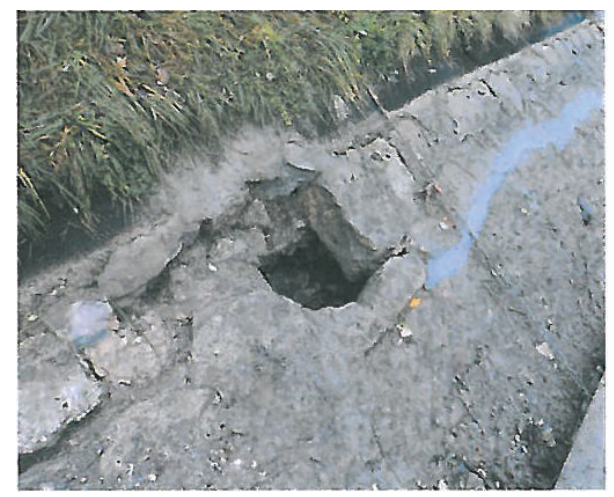

FIGURE 5: Example of serious undermining by internal erosion in the upper part of the paved revetment.

decompressed in some areas (the drill descended under its own weight).

\subsection{Morphological Characterization of the Embankment.} Figure 4 represents a transverse cross section of the embankment. The slopes of the paved revetment and the downstream structure are steep, with angles lying between 20 and $35^{\circ}$. The structure can be as high as $7 \mathrm{~m}$ in certain zones, with a base extending up to $25 \mathrm{~m}$ in width. The downstream slope is covered in grass, whereas the canal side has a paved revetment made of carved limestones blocks (masonry). Some parts of the paved-revetment have been rebuilt with concrete slabs.

Several leakage areas appeared during the last 5 years. Degraded areas were then inspected and recorded (bulging, subsidence, cracking, and holes) and the width of cracks and the depth of holes were measured [15]. Huge bulgings (35 to $160 \mathrm{~mm}$ ) and subsidence (50 to $95 \mathrm{~mm}$ ) were also observed on the paved revetment. The last leakage area was observed in 2012, with new longitudinal and vertical cracks due to unsealed stones (1 to $8 \mathrm{~mm}$ in width), some of them joining up. Huge undermining was also observed in the revetment (Figure 5).

Some of the resurgences of the observed leakages located at the foot of the embankment were around $10 \mathrm{~cm}$ in diameter (Figure 6). Given the nature of the paved revetment and the need to detect any structural voids, GPR is very suitable for an efficient use on the sloped paved revetment. Our objective, therefore, is to test this method on an embankment which is not in charge, to determine the presence of voids,

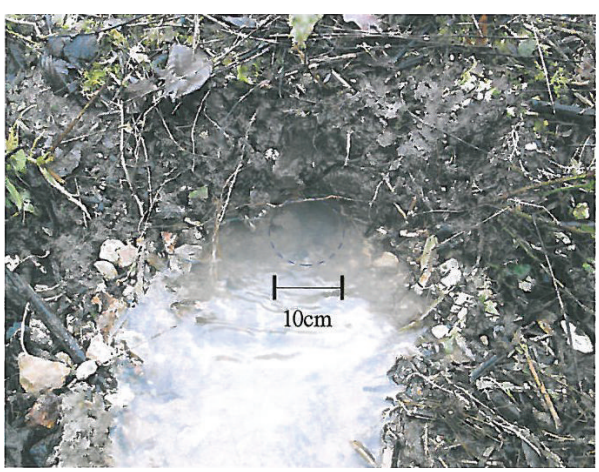

FIGURE 6: $10 \mathrm{~cm}$ diameter resurgence observed at the foot of the downstream slope.

decompressed and highly porous materials associated with leakage areas. In the following section, we present the GPR method and the protocol used on the field.

\section{Methodology}

3.1. The Principle of Ground Penetrating Radar. The GPR method is based on the study of the propagation of high frequency electromagnetic waves in the ground (from a few tens of $\mathrm{MHz}$ to several $\mathrm{GHz}$ ) [17]. These waves are generated in the form of temporal pulses at one point on the surface by an emitting antenna. The waves propagate within the soil at a speed $(\mathrm{m} / \mathrm{s})$ typical for the terrain. When the waves meet different materials, they partially reflect back to the surface, in accordance with the Snell-Descartes law. Their characteristics are then measured by another antenna (variations of the electric field amplitude caused by reflections and diffractions) and are subsequently analysed to deduce the properties of the soil. GPR helps to detect dielectric contrasts existing in the material through which the electromagnetic waves propagate. The waves are reflected in the medium, because of the dielectric contrast between materials, associated with variations in lithology, texture, porosity, material density, and particularly water content. The greater the dielectric permittivity contrast, the higher the reflection coefficient. Furthermore, to convert the time delay $t(\mathrm{~s})$ of the reflected waves to depth $z(\mathrm{~m})$, we used the following formula, valid for low-loss dielectric materials:

$$
z=2 v t,
$$

with

$$
v=\frac{c}{\sqrt{\varepsilon_{r}^{\prime}}} .
$$

With $c=3 \cdot 10^{8} \mathrm{~m} \cdot \mathrm{s}^{-1}$, the speed of light in vaccum, this approximation remains valid for low-loss mediums or with a real conductivity such as $\sigma^{\prime} \leq 0.01 \mathrm{~S} \cdot \mathrm{m}^{-1}$. Characteristic values for conductivity, permittivity, and speed are given in Table 1. In the more conductive mediums, the waves have low penetration, particularly when the clay content is high. 
TABLE 1: Reference values for conductivity, relative permittivity, and wave speed for different media of the studied embankment, from [16].

\begin{tabular}{lccc}
\hline Medium & $\sigma^{\prime}\left(\mathrm{S} \cdot \mathrm{m}^{-1}\right)$ & $\varepsilon^{\prime}$ & $v\left(\mathrm{~m} \cdot \mathrm{ns}^{-1}\right)$ \\
\hline Air & 0 & 1 & 0.3 \\
Freshwater & 0.01 & 81 & 0.033 \\
Dry sand & 0.01 & $3-5$ & $0.12-0.17$ \\
Sand saturated with water & $10^{-4}-10^{-3}$ & 30 & $0.05-0.06$ \\
Clay & $10^{-3}-2$ & $8-12$ & 0.06 \\
Dry limestone & $10^{-4}-10^{-3}$ & $6-8$ & 0.12 \\
Concrete & $10^{-3}-10^{-1}$ & $4-10$ & $0.09-0.12$ \\
\hline
\end{tabular}

The GPR vertical resolution $r$ is relative to its capacity to detect two successive reflections and is defined by the distance $d$. In an ideal situation (Nyquist's law), $r$ can be calculated as a function of wavelength $\lambda(\mathrm{m})$ as follows [17]:

$$
r=\frac{\lambda}{4}
$$

with $\lambda=v / f, f$ being the central frequency $(\mathrm{Hz})$ of the impulsion transmitted by the GPR through the antenna. Therefore, for the frequencies of 200 and $400 \mathrm{MHz}$, the theoretical resolution $r$ is in the range $[13.3-6.6] \mathrm{cm}$ for a permittivity of 8 and [12.5-6.2] $\mathrm{cm}$ for a permittivity of 9, respectively. The depth of investigation $z i(\mathrm{~m})$ in a medium with low conductivity is given by

$$
z i=\frac{\sqrt{\varepsilon_{r}^{\prime}}}{60 \pi \sigma^{\prime}} .
$$

By using a conductivity value of $10^{-2} \mathrm{~S} \cdot \mathrm{m}^{-1}$, we obtain a theoretical depth of investigation of about $1.6 \mathrm{~m}$ for limestone (cf. Table 1). In order to obtain a good signal/noise ratio, a compromise has to be made between the signal resolution and the depth of investigation.

\subsection{GPR Acquisition Protocol and Processing. Shielded} bowtie antennas of $200 \mathrm{MHz}$ and $400 \mathrm{MHz}$ and a SIR3000 GPR (Geophysical Survey Systems, Inc.) were used along the crest and on the paved revetment, respectively (Figures 1, 2, and 6). Five parallel longitudinal GPR profiles were made at various heights on the paved revetment: $0.30,0.75,1.25,1.70$, and $2.15 \mathrm{~m}$, corresponding, respectively, to measurements $\mathrm{P} 1$, P2, P3, P4, and P5 (Figure 4). Profile P1 was very similar to P2 and is not presented. Profile P6 was made in the middle of the crest (Figure 4). As the profiles were needed to be measured on a steep slope (more than $30^{\circ}$ ), the antennas were mounted on a wheeled support and guided by ropes (Figure 7). As the speed of the GPR waves was unknown, an estimated speed of $0.1 \mathrm{~m} \cdot \mathrm{ns}^{-1}$ was used in order to estimate the depth of any anomaly on the GPR results. The maximum depth of investigation is around $2 \mathrm{~m}$ for both types of antenna, that is, a similar value to our theoretical result. The raw data obtained is processed using the ReflexW software [18]. We performed a classic data processing: static correction was used in order to take into account the surface topography. A

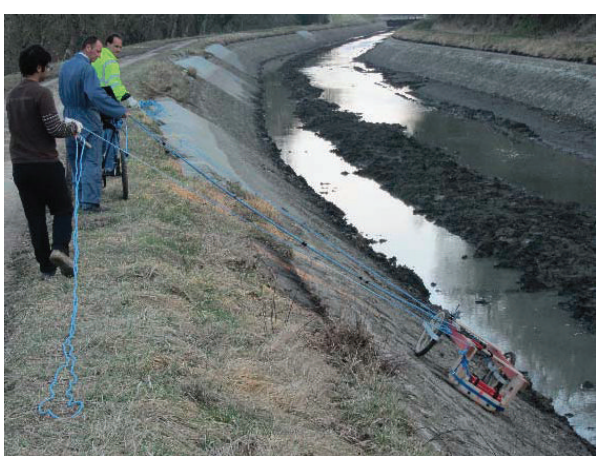

FIGURE 7: GPR acquisition on the paved revetment of the embankment.

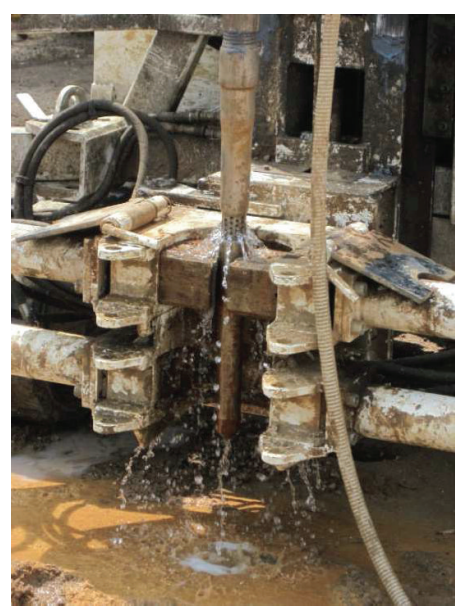

Figure 8: Photo of the Perméafor on the field.

1D (Dewow) low-pass filter correction was used to remove low frequencies disturbing the signal. A 2D (background removal) filter was applied to remove any noise coming from internal and external sources. Finally, due to the good signal/noise ratio in the medium down to the maximum depth of investigation, no gain function was applied.

\subsection{The Perméafor System: Principle and Data Acquisition} Protocol. The Perméafor [19] was developed by Cerema in the early 80s and patented in 1986 (Figure 8). This hydraulic profiling tool (HPT) provides a quick estimate of the in situ soil permeability in an almost continuous way (approximately every $20 \mathrm{~cm}$ ). The obtained permeability profile is supplemented by a penetration curve (for $20 \mathrm{~cm}$ ) to qualitatively assess the resistance to soil penetration and identify heterogeneities in the ground mass. An updated version was recently developed and used for this study (Figure 9).

The HPT tip is driven into the ground in $20 \mathrm{~cm}$ increments with the help of a drill rig using a conventional hydraulic hammer (Figure 9). When the screen is in the soil, the injection starts and is done continuously throughout the duration of the penetration. When penetration is stopped, the flow is recorded versus time for $10 \mathrm{~s}$ and then penetration is continued. 


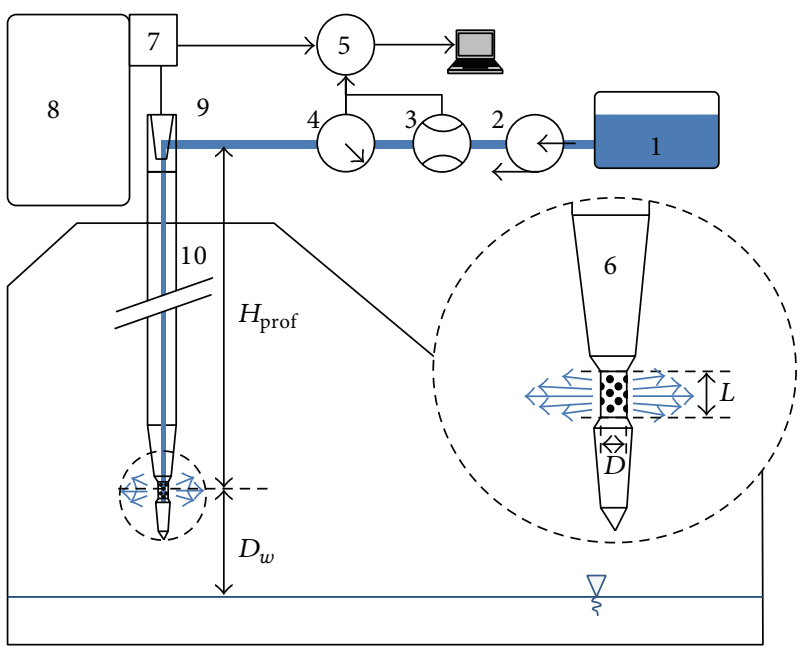

Figure 9: Scheme of the Perméafor test procedure. 1: water tank, 2: pump, 3: flow meter, 4: pressure sensor, 5: data logger, 6: patented Perméafor tip, 7: displacement transducer, 8: geotechnical drill device, 9: casing connector, and 10: conventional casing. $D$ is the diameter of the screened tip $(50 \mathrm{~mm})$ and $L$ is its length $(50 \mathrm{~mm})$.

The derived parameter $P_{k}\left(\mathrm{~m}^{2} \cdot \mathrm{s}^{-1}\right)$ computed from measurements and equivalent to permeability is

$$
P_{k}=\frac{Q}{H^{\prime}}
$$

where $Q$ is the outflow and $H^{\prime}$ is the corrected water head, defined by

$$
H^{\prime}=H_{e}+H_{\text {depth }}-D_{w}-d H(Q),
$$

where $H_{e}$ is the imposed water head, $H_{\text {depth }}$ is the height between the pump and the screen $(\mathrm{m}), D_{w}$ is the height between the screen and the water table $(\mathrm{m})$, and $d H(\mathrm{Q})$ is the pressure losses in the circuit, depending on the outflow.

The permeability $K\left(\mathrm{~m} \cdot \mathrm{s}^{-1}\right)$ is related to $P_{k}$ by the following relation [19]:

$$
K=\alpha P_{k}
$$

where

$$
\alpha=\ln \left(\frac{L}{D}+\frac{\sqrt{L^{2} / D^{2}+1}}{(2 \pi L)}\right)
$$

where $D$ is the diameter of the screened tip $(0.05 \mathrm{~m})$ and $L$ is its length $(0.05 \mathrm{~m})$.

In the range of use of the Perméafor device, the error in the measurement during a test at constant load is about 3\% and may become more important if the corrected water head becomes too low. This can occur for very permeable soils: the losses in the injection circuit tend to match the imposed load $H_{e}$, limiting the accuracy of the measurement. Thus the ratio $Q / H^{\prime}$ is generally capped at a value of $5 \cdot 10^{-3} \mathrm{~m}^{2} \mathrm{~s}^{-1}$, corresponding to highly permeable soils.

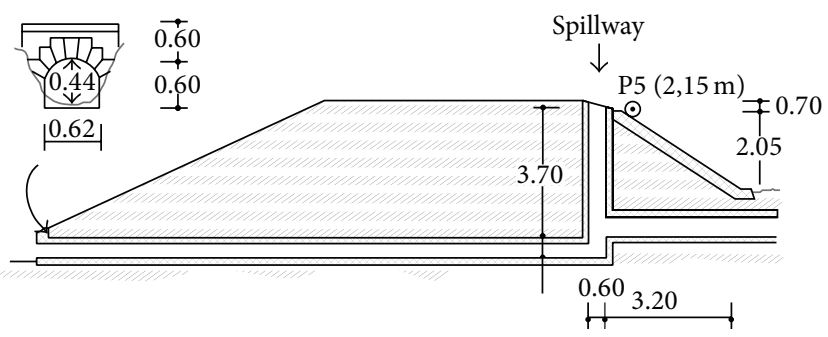

FIGURE 10: Transverse cross section of the embankment showing a spillway at $404 \mathrm{~m}$ and location of profile P5.

\section{Results and Interpretation}

First, we present the effect of a structural void (a spillway) on the GPR signal. Second, we show the results obtained along the embankment for two leakage zones and compare these measurements with deformations and sounding data.

4.1. GPR Signal for a Typical Structural Void/Cavity (Embankment Spillway). Several spillways are present within the embankment (Figure 10). The $200 \mathrm{MHz}$ GPR signal associated with one of these structures (a structural void/cavity zone) has been characterized. For that purpose, the nearest profile $\mathrm{P} 5$ was studied. Its dimensions (around $0.5 \mathrm{~m}$ wide) are in accordance with the maximum resolution obtained with the $400 \mathrm{MHz}$ antenna, that is, $0.125 \mathrm{~m}$.

Figure 11 shows the GPR profile P5 (2.15 m high) carried out on the paved revetment, just below the spillway entry. This structure is located at the end of the profile P5 (404 m). With a wave speed at $0.1 \mathrm{~m} / \mathrm{ns}$, the $200 \mathrm{MHz}$ antenna can reach a depth of investigation of about $1.70 \mathrm{~m}$ (reflection time $34 \mathrm{~ns}$ ). Two distinct diffraction hyperbolas are visible (dotted lines) at $404 \mathrm{~m}$ from $7 \mathrm{~ns}$ (at a depth of about $35 \mathrm{~cm}$ ), followed by large amplitude reflections. This observation reflects the presence of a pipe inside the embankment. The first and second hyperbolae are related to the top and the bottom of the spillway, respectively. The time delay between the two hyperbolae can be calculated using the formula $t=$ $2 d \sqrt{\varepsilon^{\prime}} / c$. Considering a pipe with a diameter $d=0.6 \mathrm{~m}$ and a permittivity $\sqrt{\varepsilon^{\prime}}=1$ for air, we obtain a time delay of about $4 \mathrm{~ns}$, that is, the time observed between the two hyperbolae (Figure 11). Therefore, this observation can be used as a reference in order to make a qualitative characterization of the presence of structural voids underneath the paved revetment.

4.2. Survey on a First Leakage Zone. Figure 12 shows the $400 \mathrm{MHz}$ profiles $\mathrm{P} 2$ and $\mathrm{P} 3$ made under the paved revetment at 0.75 and $1.25 \mathrm{~m}$ in height, up to a distance of $100 \mathrm{~m}$ from point A (Figure 2). The two profiles show an anomaly characterized by strong reflections at $70 \mathrm{~m}$, which also appears on three other profiles (P1, P4, and P5) not shown here. The 5 to $10 \mathrm{~m}$ wide anomaly starts near $6 \mathrm{~ns}$ (around $25 \mathrm{~cm}$ ), that is, under the paved revetment, and finishes at about $30 \mathrm{~ns}$ $(1.50 \mathrm{~m})$. This anomaly is located at $20 \mathrm{~m}$ downstream from the leakage (not shown here). It may correspond to an area of 


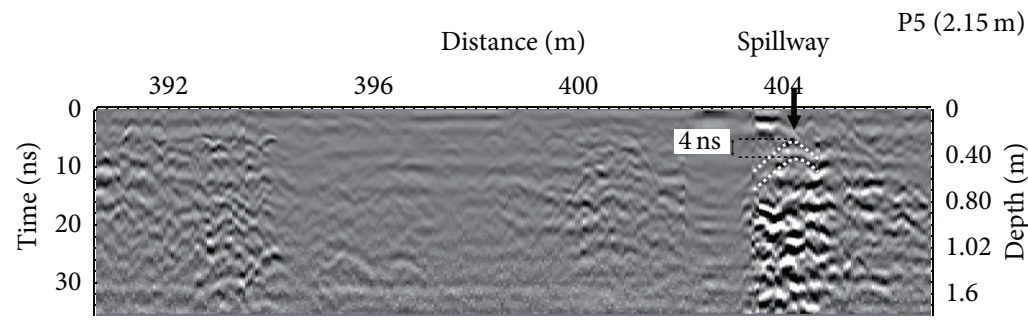

FIGURE 11: Profile P5 (200 MHz) on the paved revetment showing the hyperbolae directly above a spillway.

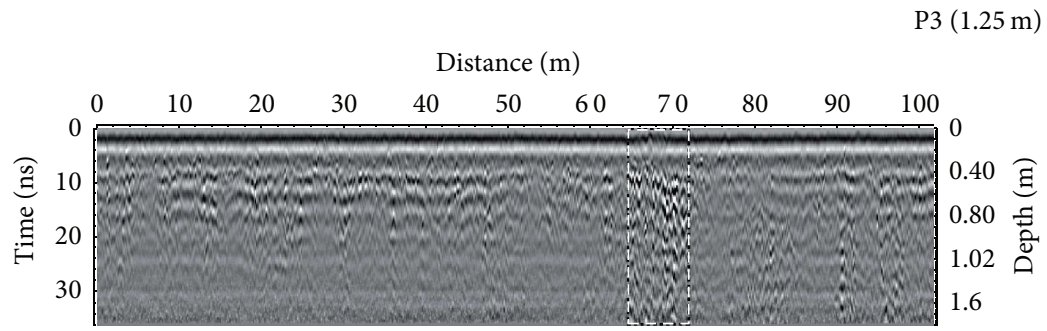

(a)

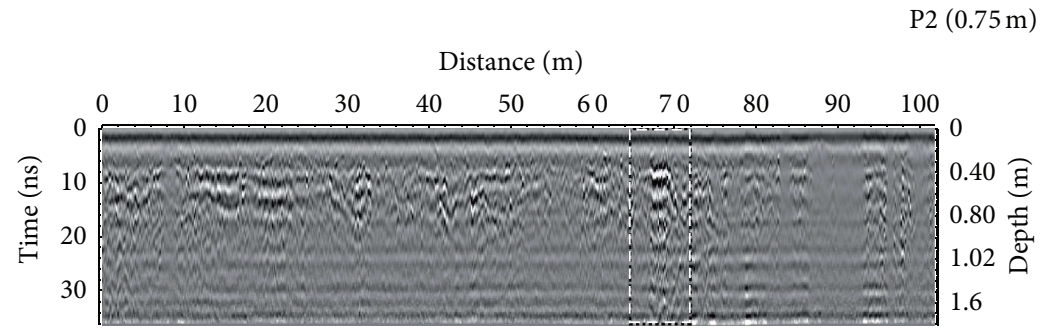

(b)

Figure 12: Possible seepage area detected with the $400 \mathrm{MHz}$ GPR on the paved revetment, associated with the 20 m downstream leakage area: (a) profile $\mathrm{P} 3$ at $1.25 \mathrm{~m}$ high; (b) profile $\mathrm{P} 2$ at $0.75 \mathrm{~m}$ high.

major water infiltration where the revetment is undermined as the fines have been washed out by the leaking water. These first $400 \mathrm{MHz}$ GPR measurements performed on the paved revetment provide a signature that can be associated with leakage areas on this embankment.

4.3. Survey on a Second Leakage Zone. The visual inspection shows that this second leakage area is the more critical zone on the embankment. Therefore, a more complete survey was carried out, including $200 \mathrm{MHz}$ and $400 \mathrm{MHz}$ GPR measurements, coring data, and permeability logging.

4.3.1. $200 \mathrm{MHz}$ and $400 \mathrm{MHz}$ GPR Survey. Figure 13(a) shows the data obtained with the $200 \mathrm{MHz}$ antenna on the crest (profile P6) below the $\mathrm{S} 1$ coring at $167 \mathrm{~m}$ (Figure 2). As the waves' speed is fixed at $0.1 \mathrm{~m} \cdot \mathrm{ns}^{-1}$, a time delay of $40 \mathrm{~ns}$ corresponds to a depth of about $2 \mathrm{~m}$. In fact, two layers are easily observed on this profile. The limit of the first layer is underlined by a major reflection at about $12 \mathrm{~ns}(50 \mathrm{~cm})$. This layer may be associated with the silty-sand material present in some areas of the embankment. Underneath this layer, heterogeneous zones are observed, corresponding to the limestone sand-gravel material with a clay matrix (formation A, see Section 2.1), as shown in Figure 3. Lateral variations of the reflected signals are visible along the profile: they reflect changes in the nature of the materials in the body of the embankment. An attenuated GPR signal area located between $175 \mathrm{~m}$ and $198 \mathrm{~m}$ at $70 \mathrm{~cm}$ depth (dotted line square in Figure 13(a)) is typical of a clayey content material.

In the same profile, a more heterogeneous zone is observed between $160 \mathrm{~m}$ and $175 \mathrm{~m}$ and at $60 \mathrm{~cm}$ depth. This zone is characterized by a much contrasted $200 \mathrm{MHz}$ GPR signal, similar to the spillway response and to the heterogenous area observed in Figure 12. It includes several diffraction hyperbolae, typical of a relatively resistive medium. This anomaly is very close to the second leakage area exactly located at the foot of the downstream slope (see in situ observation shown in Figure 6). The seepage was probably responsible for washing out the fine particles (clay and silt, i.e., conductive particles), keeping in place the limestone gravels (see Figure 3).

Figures 13(b) and 13(c) present the $400 \mathrm{MHz}$ GPR profiles $\mathrm{P} 4$ and $\mathrm{P} 5$ performed on the paved revetment at $1.70 \mathrm{~m}$ and $2.15 \mathrm{~m}$ high, respectively. The attenuated signal between $140 \mathrm{~m}$ and $170 \mathrm{~m}$ and between $190 \mathrm{~m}$ and $200 \mathrm{~m}$ corresponds to 


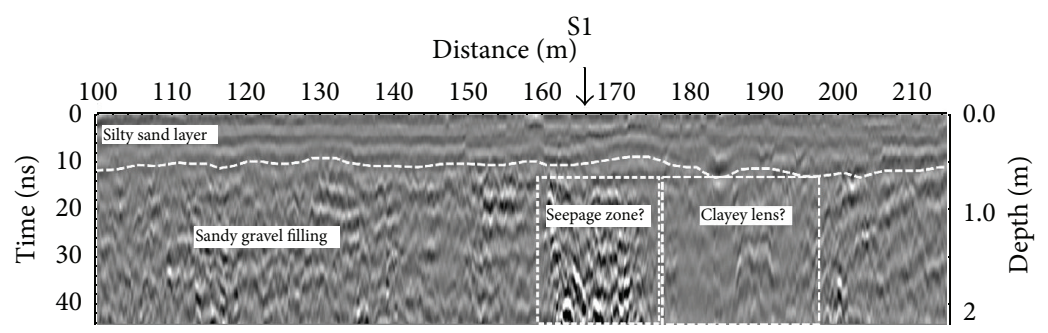

(a)

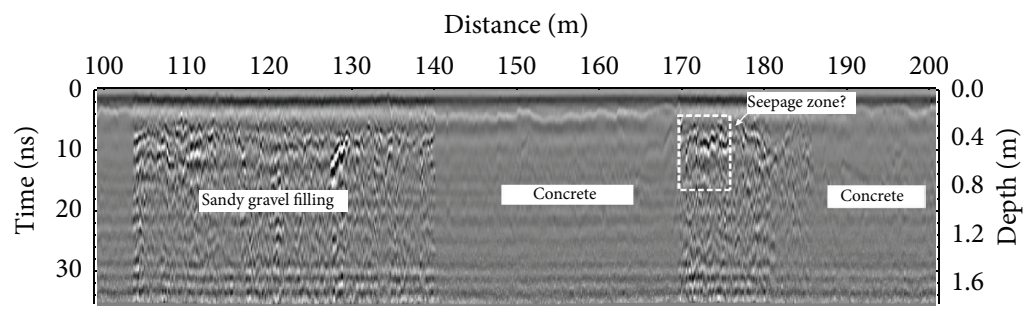

(b)

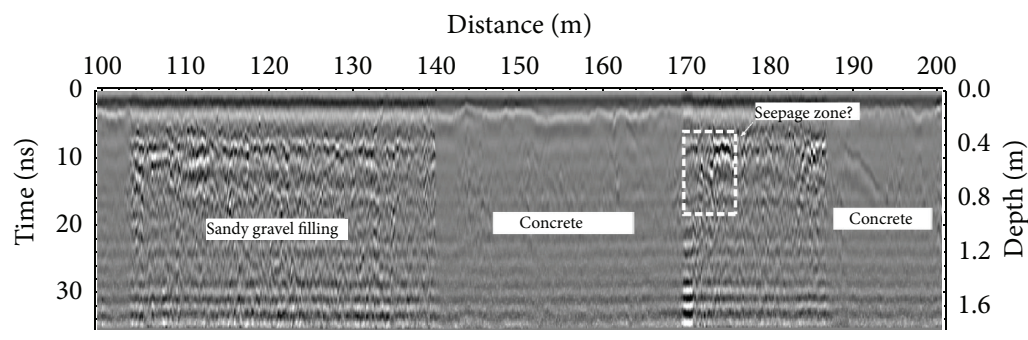

(c)

FIGURE 13: GPR signal associated with the second leakage zone. (a) GPR profile P6 on the crest (200 MHz); (b) GPR profile P5 on the paved revetment at $2.15 \mathrm{~m}$ high $(400 \mathrm{MHz})$; (c) GPR profile P4 of the paved revetment at $1.7 \mathrm{~m}$ high $(400 \mathrm{MHz})$.

previous repairs with concrete (i.e., an absorbing material). The heterogeneous zone observed on the $400 \mathrm{MHz}$ profiles located between $170 \mathrm{~m}$ and $176 \mathrm{~m}$ (time delay and depth in the range [4-16] ns and [20-80] cm, resp., see Figures $13(\mathrm{~b})$ and $13(\mathrm{c})$ ) corresponds to the extremity of the seepage area on the $200 \mathrm{MHz}$ crest profile.

4.3.2. Perméafor Results. The Perméafor measurement (Figure 14) was only carried out on the second leakage area. The equivalent permeability logging was exactly performed on the S1 location, that is, on the crest (see Figure 13(a)), and close to the leakage zone observed on the paved revetment. Such testing cannot be performed on the slopes. Between 1 and $2 \mathrm{~m}$, the permeability drastically increases from $10^{-4}$ to $10^{-3} \mathrm{~m}^{2} \cdot \mathrm{s}^{-1}$ and is typical of highly permeable soils. This result is perfectly correlated with the GPR section showing highly resistive materials and strong hyperbolae typical of gravels and sandy materials. Moreover, the S1 coring (Figure 3) performed one year before this study and exhibiting highly heterogeneous soils up to $3 \mathrm{~m}$ depth corroborates both the Perméafor and GPR results.

\section{Discussion}

The first survey conducted with the $200 \mathrm{MHz}$ antenna above a spillway (P5 profile) provides the typical signature of a void within this embankment. This result remains limited: the spillway diameter is important and close to the surface, even though smaller/deeper voids, undetectable by the GPR, may be responsible for major damages.

The $400 \mathrm{MHz}$ GPR survey on the first leakage area (P2 and P3 profiles) was performed on the paved revetment. The measurements show unconsolidated areas that may be linked to the observed leakage. $200 \mathrm{MHz}$ GPR survey on the crest (not shown here) did not provide consistent results for this part of the embankment. First, the materials are probably too conductive and limit the GPR application. Second, the seepage area and pathways may be too deep to be detected. Third, the acquisition protocol (Figure 7) renders difficult the good maintenance of the antenna along its way.

The survey on the second leakage zone (P4, P5, and P6 profiles) is more complete, combining geophysical and geotechnical methods. The embankment is mainly composed of two layers observed on the $200 \mathrm{MHz}$ GPR results, corroborated with the coring data. Moreover, a possible seepage area is underlined from the crest and corresponds to an unconsolidated zone, detected with the $400 \mathrm{MHz}$ antenna underneath the paved revetment. Last but not the least, this possible seepage area is, first, in accordance with the Perméafor results and, second, exactly located above the leakage area. Nevertheless, the GPR investigation remains limited because of the presence of concrete repairs on the paved revetment and 


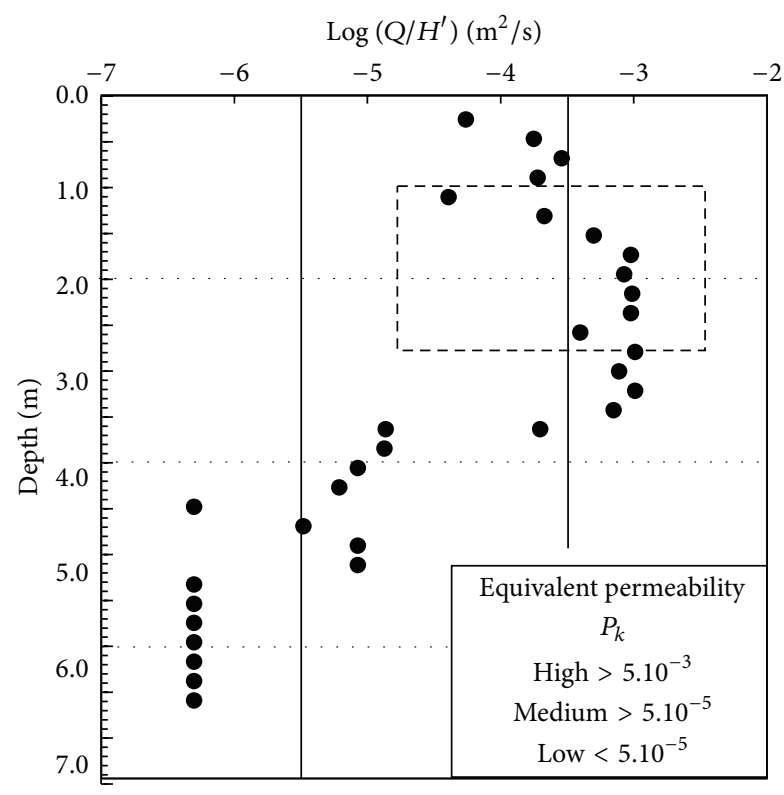

(a)

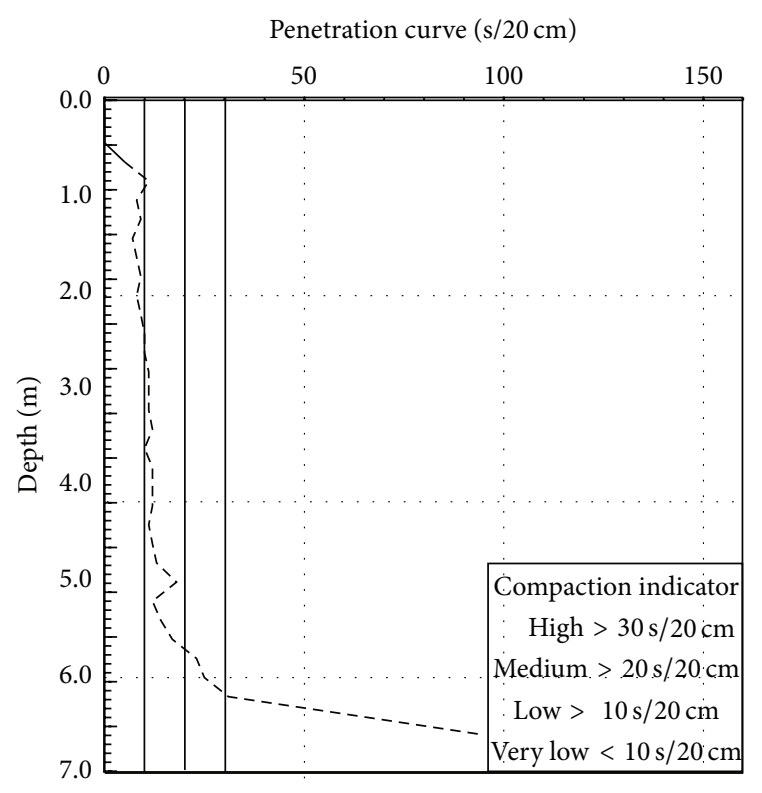

(b)

FIgURE 14: (a) Equivalent permeability $P_{k}$ obtained with the Perméafor located on $S 1$ and (b) associated penetration curve.

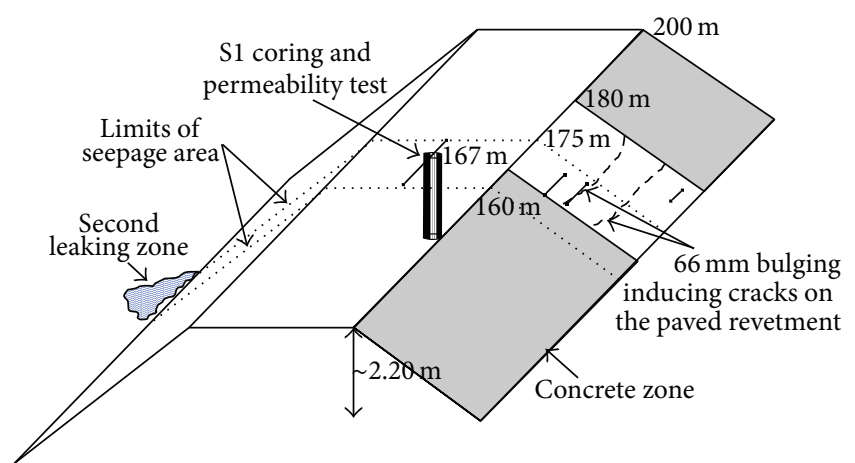

FiguRE 15: Sketch of the reported anomaly for the second leakage area (S1 coring and permeability testings at 167 m; see also Figure 13).

clay within the embankment core. Indeed, these materials deeply attenuate electromagnetic waves. Our measurements were performed in unsaturated conditions. The same type of survey could have been carried out in hydraulic charge conditions. First, as the water dielectric constant is about 81 in the GPR frequency range, the electromagnetic contrast would have been more favourable to the seepage area detection. Second, the comparison between dry and wet conditions would have been relevant for a cross analysis of the GPR profiles.

Figure 15 presents (i) all the GPR anomalies detected during the survey on the second leakage zone and (ii) areas of degradation recorded during visual inspections of the canal. A $66 \mathrm{~mm}$ bulging area in the centre of the paved revetment was observed. The presence of bulging in the lower or middle parts is associated with deformation and undermining below the revetment (see Figure 13). The medium has probably been washed of its fines, inducing favourable conditions of seepage. Undermining induced an important compressive stress on the paved revetment, generating bulging as well as longitudinal cracking. Bulging is also observed in the concrete repairs and is not correlated with the nature of the suface revetment (limestones blocks or concrete repairs).

In order to complete this study, other methods such as low frequency electromagnetic induction (FDEM) and multichannel analysis of seismic surface wave (MASW) may provide a more accurate zoning of unconsolidated areas in the embankment core.

\section{Conclusion}

GPR measurements were carried out on an earth embankment (crest and paved revetment) of a Loire canal, a $400 \mathrm{~m}$ long structure, free of hydraulic charge. The measurements show heterogeneous materials within this embankment. The GPR signals are significantly attenuated in certain areas, corresponding to repairs (concrete), clayey materials, and high water content in the soil. Moreover, individual drain may not be detected with this method due to its potential millimetric/centimetric dimensions, under the detection threshold of the GPR method.

The measurements performed on the crest of the embankment with the $200 \mathrm{MHz}$ antenna confirm the lithology observed with the coring samples. The typical signature of a structural void/cavity in the embankment of a few tens of centimetres wide has also been identified. This signature followed by an in situ qualitative calibration provides a typical and recognisable GPR signature of a structural void. Based on this observation, several anomalies were detected and interpreted as potential voids. Two leakage zones were presented in this paper. The anomalies are characteristic 
by their strong GPR reflections, either with the $400 \mathrm{MHz}$ antenna on paved revetment or with the $200 \mathrm{MHz}$ antenna on the crest. They are also characterized by a high permeability, obtained using the Perméafor. These anomalies can be linked to lithology and porosity variations, material decompression and subsidence. GPR remains a useful tool for embankment diagnosis: (i) it is easy to implement in the field; it provides (ii) real time observations, (iii) detailed information concerning potential structural voids or decompressed areas, and (iv) complementary results with classical geotechnical testings, as well as innovative methods such as the Perméafor.

\section{Conflict of Interests}

The authors declare that there is no conflict of interests.

\section{Acknowledgments}

The authors would like to thank Bruno Beaucamp and Cyril Ledun who helped to carry out GPR measurements on the field. This work was supported by the Ifsttar/Cerema research program DOFEAS.

\section{References}

[1] E. Niederleithinger, A. Weller, and R. Lewis, "Evaluation of geophysical techniques for dike inspection," Journal of Environmental \& Engineering Geophysics, vol. 17, no. 4, pp. 185-195, 2012.

[2] A. Loperte, M. Bavusi, G. Cerverizzo, V. Lapenna, and F. Soldovieri, "Ground penetrating radar in dam monitoring: the test case of acerenza (Southern Italy)," International Journal of Geophysics, vol. 2011, Article ID 654194, 9 pages, 2011.

[3] C. Fauchard and P. Mériaux, Geophysical and Geotechnical Methods for Diagnosing Flood Protection Dikes, Editions Quae, 2007.

[4] K. Samyn, F. Mathieu, A. Bitri, A. Nachbaur, and L. Closset, "Integrated geophysical approach in assessing karst presence and sinkhole susceptibility along flood-protection dykes of the Loire River, Orléans, France," Engineering Geology, vol. 183, pp. 170-184, 2014.

[5] T. V. Panthulu, C. Krishnaiah, and J. M. Shirke, "Detection of seepage paths in earth dams using self-potential and electrical resistivity methods," Engineering Geology, vol. 59, no. 3-4, pp. 281-295, 2001.

[6] M. T. Perri, J. Boaga, S. Bersan et al., "River embankment characterization: the joint use of geophysical and geotechnical techniques," Journal of Applied Geophysics, vol. 110, pp. 5-22, 2014.

[7] M. Di Prinzio, M. Bittelli, A. Castellarin, and P. R. Pisa, "Application of GPR to the monitoring of river embankments," Journal of Applied Geophysics, vol. 71, no. 2-3, pp. 53-61, 2010.

[8] R. Mydlikowski, G. Beziuk, and A. Szynkiewicz, "Detection of inhomogeneities in structure of flood embankments by means of d.c. resistivity, gpr and frequency electromagnetic method measurements," Acta Geodynamica et Geomaterialia, vol. 4, no. 4, pp. 83-88, 2007.

[9] S. Carlsten, S. Johansson, and A. Wörman, "Radar techniques for indicating internal erosion in embankment dams," Journal of Applied Geophysics, vol. 33, no. 1-3, pp. 143-156, 1995.
[10] K. Preko, A. Scheuermann, and H. Wilhelm, "Comparison of invasive and non-invasive electromagnetic methods in soil water content estimation of a dike model," Journal of Geophysics and Engineering, vol. 6, no. 2, pp. 146-161, 2009.

[11] X. Xu, Q. Zeng, D. Li, J. Wu, X. Wu, and J. Shen, "GPR detection of several common subsurface voids inside dikes and dams," Engineering Geology, vol. 111, no. 1-4, pp. 31-42, 2010.

[12] A. Bolève, A. Crespy, A. Revil, F. Janod, and J. L. Mattiuzzo, "Streaming potentials of granular media: influence of the Dukhin and Reynolds numbers," Journal of Geophysical Research B: Solid Earth, vol. 112, no. 8, Article ID B08204, 2007.

[13] A. Rozycki, C. Olalla, J. M. Ruiz Fonticiella, and A. Cuadra, "Underwater self-potential measurements in the safety assessment of dams," Near Surface Geophysics, vol. 6, no. 5, pp. 307314, 2008.

[14] A. Rozycki, J. M. R. Fonticiella, and A. Cuadra, "Detection and evaluation of horizontal fractures in earth dams using the selfpotential method," Engineering Geology, vol. 82, no. 3, pp. 145153, 2006.

[15] E. Durand, "Reconnaissance geophysique, geotechnique et diagnostique de stabilite de la zone fuyarde situe e entre les aqueducs de la gare et de la Motte (Saint Firminsur-Loire)," Tech. Rep., Cerema, 2012.

[16] G. Palacky, "Electromagnetic methods in applied geophysics," in Resistivity Characteristics of Geologic Targets, Geophysical Developments Series. Society of Exploration Geophysicists, pp. 52-129, 1988.

[17] D. Daniels, Ground Penetrating Radar, vol. 15 of IEE Radar, Sonar, Navigation and Avionics Series, The Institution of Electrical Engineers, HERTS. MPG Books, Bodmin, UK, 2nd edition, 2004.

[18] K. Sandmeier, ReflexW version 3.5. Program for Processing of Seismic, Acoustic and Electromagnetic Reflection, Refraction and Transmission Data. Software Manual, Karlsruhe, Germany, 2004.

[19] P. Reiffsteck, B. Dorbani, E. Haza-Rozier, and J. Fry, "A new hydraulic profiling tool including cpt measurements," in Proceedings of the 2nd International Symposium on Cone Penetration Testing (CPT '10), May 2010. 

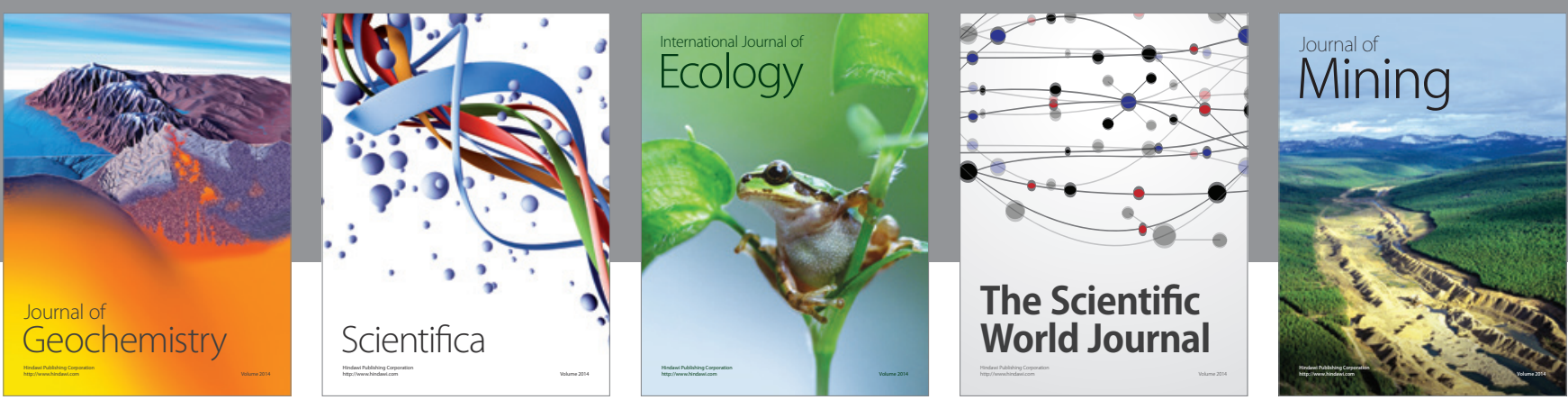

The Scientific World Journal
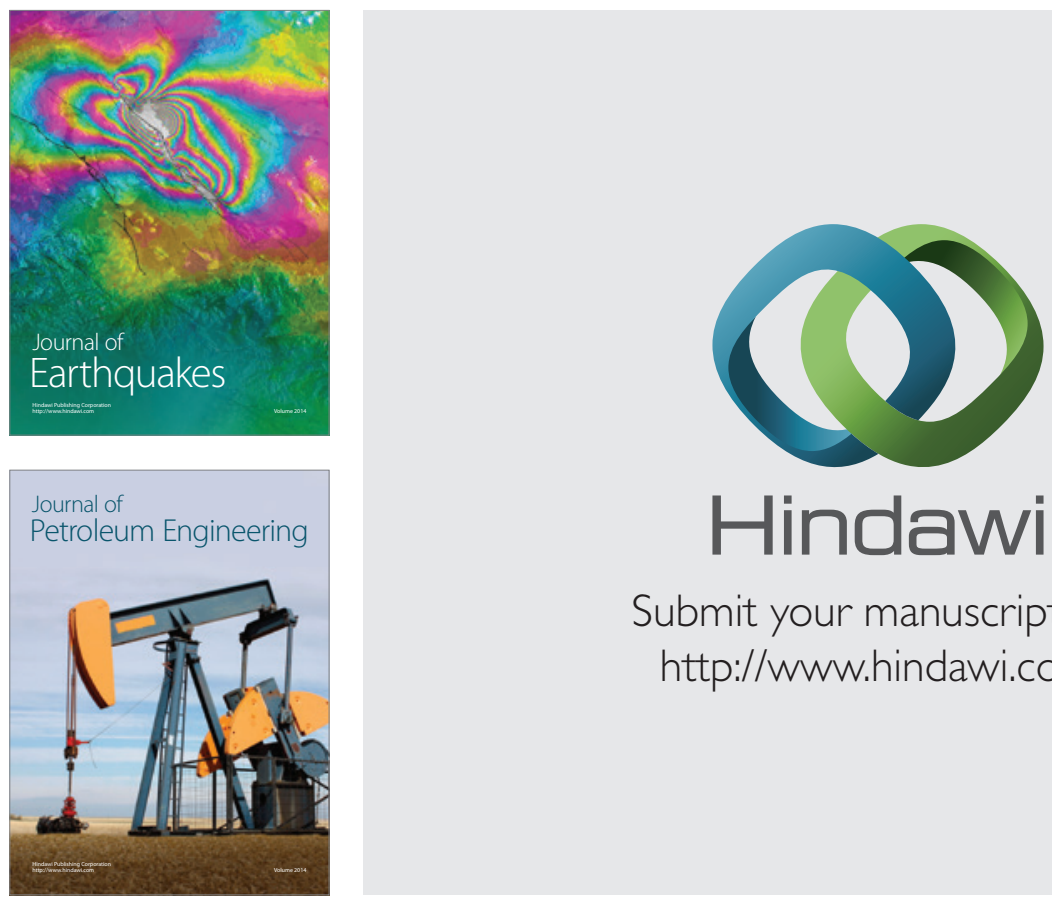

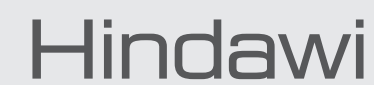

Submit your manuscripts at

http://www.hindawi.com
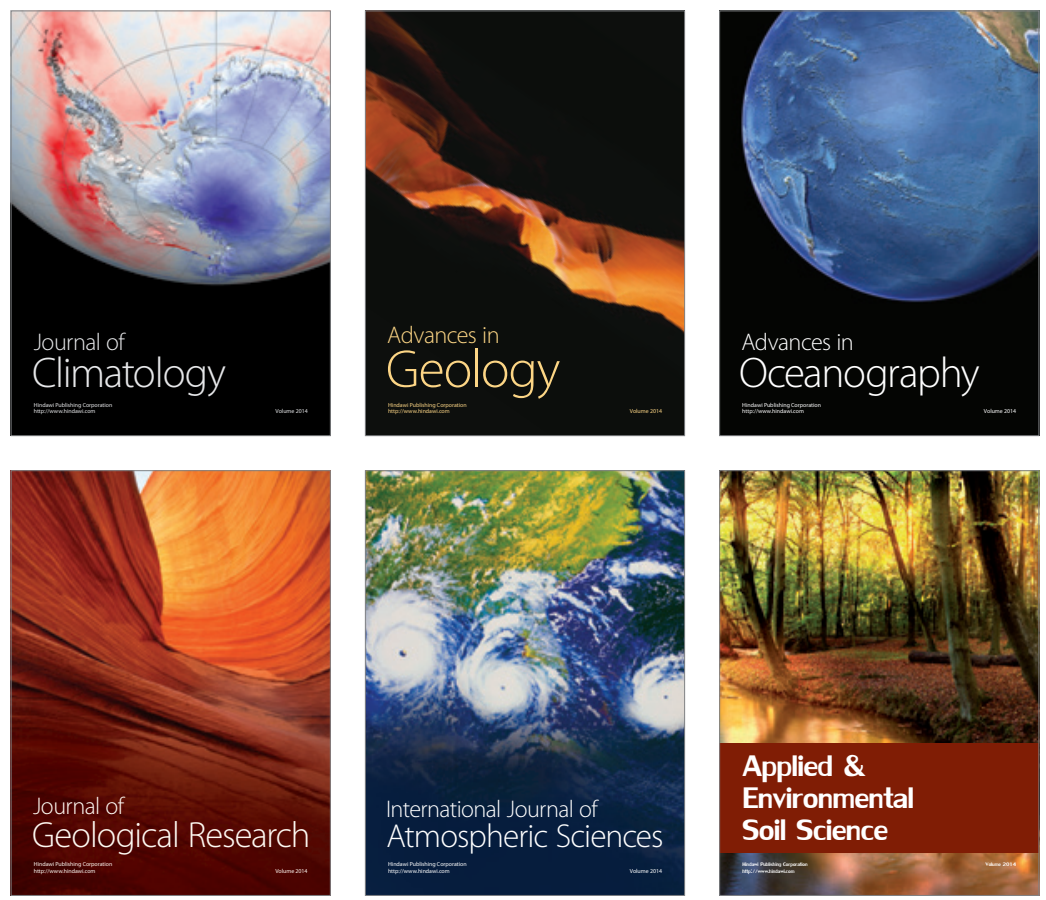
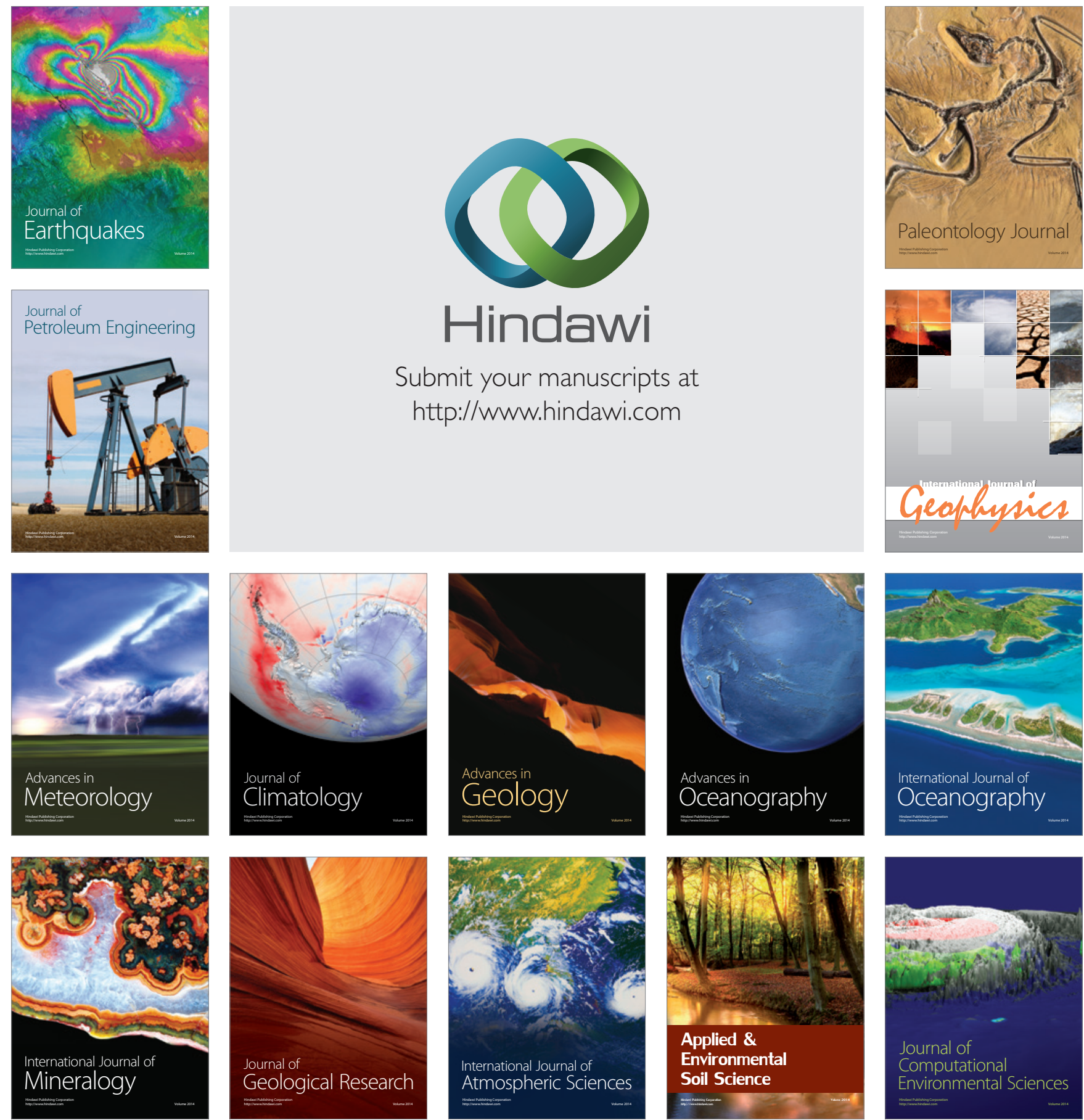